\title{
: SHELL-CRUSHING BY TWO DUCK SPECIES, TADORNA TADORNA AND SOMATERIA MOLLISSIMA IN THE WADDEN SEA. PALEOECOLOGIC IMPLICATIONS
}

CADEE, Gerhard C, Netherlands Institute for Sea Research, PO Box 59, 1790 AB Den Burg, Texel, the Netherlands

Shell fragments from faeces of the mollusc-eating eider (Somatera mollissima) and shelduck (Tadorna tadorna) were studied in the Dutch Wadden sea. Both species crush shells internally in their gizzard.

Shelducks feed mainly on the small gastropod Hydrobia ulvae, which they do not always succeed in breaking: in some cases even surviving Hydrobia were collected from the faeces. This indicates that shelduck may help dispersion of Hydrobia and that not only Hydrobia fragments but also intact empty shells are contributed to the sediment by this predator.

Eiders feed mainly on mussels (Mytilus edulis) and cockles (Cerastoderma edule). When these are scarce, they take shorecrabs or the gastropod Littorina littorea. Their crushing method is usually successful; only some Littorina shells were found intact but not alive in their faeces. Shells are crushed to fragments ranging from less than 0.1 to $8 \mathrm{~mm}$, with a peak in the $2-4 \mathrm{~mm}$ size fraction, $20 \%$ was $<1 \mathrm{~mm}$.

Annual shell carbonate production in the Dutch Wadden Sea is ca 150.000 tonnes. The annual average number of eiders is 63.000 with a maximum of up to 200.000 in winter. Annually they consume 3200 tonnes meat (ash-free dryweight). If they fed fifty/fifty on mussels and cockles they would produce ca, 75.000 tonnes shell-fragments. As they feed partly on non-molluscan food this is an upper limit, but it implies that they are the main producers of shell-fragments (of all sizes, even the smallest) in the Wadden Sea. The typically square shell-fragments they produce, are easily recognisable in Wadden sea sediments.

Others predators (shorecrabs, shrimps, flatfish, other molfusceating birds like knot and curlew) produce additional shell-fragments. However, some predators e.g. seastars (Asterias rubens) leave intact the shells they consumed.

Shell-fragments in sediments, therefore, may give an indication of predation pressure, but as non-crushed shells may be left over by some predators, total predation pressure on molluscs cannot be estimated in fossil faunas. 